\title{
FAKTOR PENYEBAB PERUBAHAN MORFOLOGI DESA NGADAS, PONCOKUSUMO, KABUPATEN MALANG
}

\author{
Dian Kartika Santoso ${ }^{1 a}$, Respati Wikantyoso ${ }^{2}$ \\ ${ }^{1 .}$ Mahasiswa S2 Arsitektur Lingkungan Binaan Universitas Brawijaya \\ 2.Guru Besar bidang Arsitektur Universitas Merdeka Malang \\ adiankartikasantoso@gmail.com
}

\begin{tabular}{ll}
\hline & Abstract \\
\cline { 2 - 2 } $\begin{array}{l}\text { Keywords: } \\
\text { Ngadas, Dynamics, } \\
\text { Morphology }\end{array}$ & $\begin{array}{l}\text { Ngadas Village has been designated as Tourism Village. Such determination may affect } \\
\text { the morphology of Ngadas Village. Although tourism activities are regarded as things } \\
\text { that can cause changes in the morphology of the region, but do not rule out the possibility } \\
\text { of other factors. Thus, it is very important to know the factors other causes. Thus, massive } \\
\text { morphological changes can be controlled by knowing the causal factors. Consequently, } \\
\text { the sustainability of Ngadas as a traditional tourism village can be maintained. Method } \\
\text { used in this research is descriptive qualitative method through synchronic and diachronic } \\
\text { approach. In addition, this research also used spatial analysis to know morphology's } \\
\text { development of Ngadas Village through Google Earth image in 2004, 2012, and 2017. The } \\
\text { result of research indicates that factors causing morphological change of Ngadas Village } \\
\text { are cultural factor, natural factor, demographic favtor, tourism development factor, build- } \\
\text { ing and land allotment, and government policy. }\end{array}$ \\
&
\end{tabular}

Abstrak

Kata Kunci:

Ngadas,

Dinamika,

Morfologi

Desa Ngadas telah ditetapkan sebagai Desa Wisata. Penetapan tersebut dapat mempengaruhi morfologi Desa Ngadas. Meskipun kegiatan pariwisata dianggap sebagai hal yang dapat menyebabkan perubahan morfologi kawasan, namun tidak menutup kemungkinan adanya faktor lain. Sehingga, sangat penting untuk mengetahui faktorfaktor penyebab lain. Sehingga, perubahan morfologi yang massif dapat dikendalikan dengan mengetahui faktor penyebabnya. Dampaknya, keberlangsungan Ngadas sebagai Desa Wisata Adat dapat terjaga. Metode yang digunakan dalam penelitian ini adalah metode kualitatif deskriptif melalui pendekatan sinkronik dan diakronik. Selain itu, penelitian ini juga menggunakan analisis spasial untuk mengetahui perkembangan morfologi Desa Ngadas melalui citra Google Earth tahun 2004, 2012, dan 2017.Hasil penelitian menunjukkan bahwa faktor penyebab perubahan morfologi Desa Ngadas adalah faktor budaya, alam, demografi, faktor berkembangnya pariwisata, perubahan tata masa bangunan dan peruntukan lahan, serta kebijakan pemerintah.

@ 2017 The Authors. Published by GKAK UNMER Malang

*Corresponding Author: diankartikasantoso@gmail.com 


\section{Pendahuluan}

Desa Ngadas adalah sebuah desa yang mayoritas didiami oleh Suku Tengger di wilayah Kabupaten Malang (Agustapraja, 2017; Andriyani, 2017; Endarwati, 2013; Listiyana \& Mutiah, 2017). Kenikan yang dimiliki Ngadas dari segi geografis dan budaya membuat pemerintah Kabupaten Malang menjadikan Ngadas sebagai Desa Wisata pada tahun 2007 (Listiyana \& Mutiah, 2017). Hal ini semakin diperkuat dengan kebijakan pemerintah yang memproyeksikan Desa Ngadas sebagai Desa Wisata Adat (Anggiana \& Bergas, 2014). Sebuah Desa ditetapkan sebagai Desa Wisata Adat karena adanya daya tarik yang dimiliki seperti pola tata ruang desa dan arsitektur tradisional rumah penduduknya (Andriyani, 2017).

Pola tata ruang merupakan salah satu kekuatan Ngadas sebagai Desa Wisata. Namun, dengan adanya kegiatan pariwisata dikhawatirkan mempengaruhi pola tata ruang atau morfologi Kawasan. Hal ini sesuai dengan penelitian sebelumnya yang menyebutkan bahwa pola tata ruang dapat berkembang karena adanya faktor wisata (Nadjmi, 2016).

Meskipun kegiatan pariwisata dianggap sebagai hal yang dapat menyebabkan perubahan morfologi Kawasan, namun tidak menutup kemungkinan adanya faktor lain. Sehingga, sangat penting untuk mengetahui faktor-faktor penyebab lain. Sehingga, perubahan morfologi yang massif dapat dikendalikan dengan mengetahui faktor penyebabnya. Dampaknya, keberlangsungan Ngadas sebagai Desa Wisata Adat dapat terjaga.

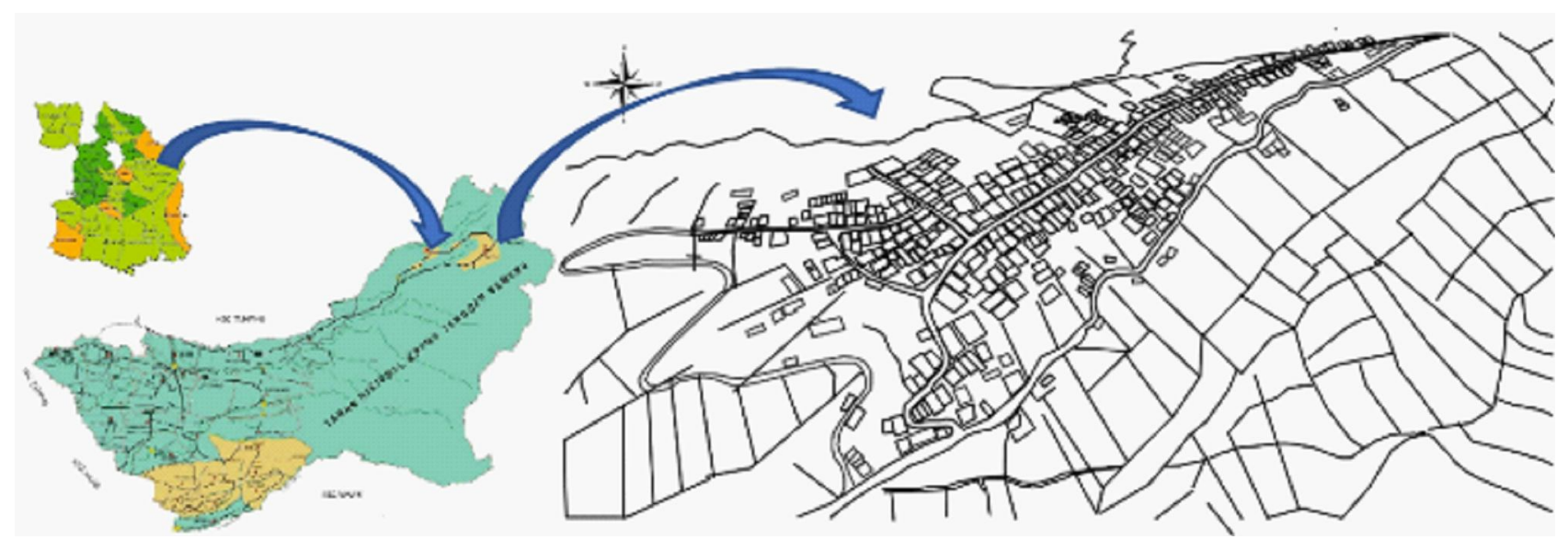

Gambar 1. Lokasi Desa Ngadas

(Sumber: diolah dari Google Earth 2017 dengan AutoCAD 2014)

\section{Permasalahan}

Permasalahan yang diangkat dalam penelitian ini faktor-faktor penyebab perubahan morfologi Desa Ngadas. Perubahan morfologi tersebuat dikaitkan dengan kegiatan wisata serta kondisi alam serta budaya masyarakat Ngadas. 


\section{Tujuan Penulisan/Pembahasan}

Penelitian ini bertujuan untuk mengetahui perubahan morfologi di Desa Ngadas. Selanjutnya, penelitian ini juga bertujuan untuk mengetahui faktor-faktor penyebab perubahan morfologi Desa Ngadas.

\section{Metode}

Metode yang digunakan dalam penelitian ini adalah metode kualitatif deskriptif melalui pendekatan sinkronik dan diakronik. Pendekatan sinkronik berhubungan dengan gejala dalam cakupan yang luas namun dalam waktu yang terbatas. Sedangkan pendekatan diakronik berhubungan dengan proses atau waktu, dan sejarah. Kedua pendekatan ini dianggap penting dalam kajian arsitektur Nusantara, khususnya untuk mengetahui perkembangan regionalisme arsitektur (Hidayatun, Prijotomo, \& Rachmawati, 2014). Dalam kajian ini, pendekatan dilakukan pada komponen morfologi berupa tata guna lahan, struktur bangunan, pola plot, dan jaringan jalan (Carmona, 2003).

Selain itu, penelitian ini juga menggunakan analisis spasial untuk mengetahui perkembangan morfologi Desa Ngadas. Analisis spasial bersumber dari peta Kawasan yang diolah dari citra satelit Google Earth. Dalam penelitian, peneliti terkadang harus membeli citra satelit resolusi tinggi terbaru yang lebih mahal membeli dan terkadang tidak mungkin mendapatkan data karena alasan keamanan. Solusi alternatif yang dapat dimanfaatkan adalah citra satelit Google Earth yang merupakan sumber terbuka dan memberikan gambaran yang jelas tentang bangunan, jalan, dll (Malarvizhi, Kumar, \& Porchelvan, 2016). Google Earth sangat memfasilitasi analisis cepat dengan menggunakan infrastruktur komputasi Google (Zurqani, Post, Mikhailova, Schlautman, \& Sharp, 2018) dan dapat digunakan secara mudah untuk mendapatkan peta digital (Pulighe \& Lupia, 2016). Citra satelit yang digunakan dalam penelitian ini didasarkan pada ketersediaanya, sehingga dibagi menjadi tiga waktu, yaitu tahun 2004, 2012, dan 2017.

Tahapan yang dilakukan dalam penelitian beserta cara memperoleh data, dapat dilihat pada Tabel 1.

Tabel 1. Tahapan penelitian, teknik, dan sumber perolehan data

\begin{tabular}{llll}
\hline \multicolumn{1}{c}{ Tahapan } & \multicolumn{1}{c}{$\begin{array}{c}\text { Teknik yang } \\
\text { digunakan }\end{array}$} & \multicolumn{1}{c}{ Sumber } & Alat dan Bahan \\
\hline Studi Pendahuluan & Literature review & Penelitian terdahulu & Jurnal \\
\hline Pengumpulan Data & Observasi & Lapangan & Alat tulis \\
& Wawancara & Masyarakat & Daftra pertanyaan \\
& Dokumentasi & Instansi Pemerintah & Kamera \\
& Literature review & Penelitian terdahulu & Dokumen pemerintah \\
& Pemetaan & Citra Satelit & Jurnal \\
& & & Komputer \\
& & & Citra Google Earth \\
& & & AutoCAD 2014 \\
& Analisis Deskriptif & Hasil identifikasi perubahan & Peta \\
& dan Spasial & morfologi dan penyebabnya & Daftar wawancara dan observasi \\
& & & Jurnal \\
& & & Dokumen pemerintah \\
\hline
\end{tabular}

\section{Kesimpulan}


LOCAL WISDOM, Vol. 10 No. 2 Juli 2018

Local Wisdom Scientific Online Journal

\section{Tata Guna Lahan}

Secara umum, tata guna lahan di Desa Ngadas tidak berubah jika dilihat dari fungsi umumnya. Tata guna lahan didominasi oleh ladang, permukiman, dan dibatasi oleh hutan Taman Nasional Bromo Tengger Semeru. Perkembangan tata guna lahan di Ngadas dapat dilihat pada Tabel 2.

Tabel 2. Perkembangan Tata Guna Lahan di Desa Ngadas

2004


Jika dilihat dari proporsinya, ladang mendominasi penggunaan lahan di Desa Ngadas dari tahun ke tahun. Hal ini diakibatkan adanya budaya masyarakat mengenai tradisi pewarisan lahan. Kepemilikan ladang dalam area yang luas selain berasal dari warisan langsung dari orang tua mereka, juga diperoleh dari kerabat terdekat karena merawat masa tuanya, seperti adik orang tua, maupun kerabat lain (Agustapraja, 2017).

\section{Tata Masa Bangunan}

Masyarakat Ngadas memiliki aturan tersendiri di dalam penataan masa bangunan. Desa dibagi menjadi tiga zona, yaitu kaki sebagai tempat yang dianggap tempat yang fana, dan peruntukannya adalah permukiman, kemudian badan untuk bangunan sosial seperti balai desa dan sekolah, sedangkan yang paling suci adalah bagian kepala yaitu tempat ibadah dan makam (Agustapraja, 2017; Endarwati, 2013). Hal ini juga sejalan dengan prinsip Suku Tengger lain di kawasan TNBTS, seperti di Desa Wonokitri maupun Sukapura (Ayuninggar, Antariksa, \& Wardhani, 2012; Ayuninggar, Antariksa, \& Wardhani, 2013). Hal ini berpengaruh pada morfologi Desa yang semakin sempit pada bagian kepala, karena tidak banyak hunian berada pada area yang dianggap suci (Gambar 2).

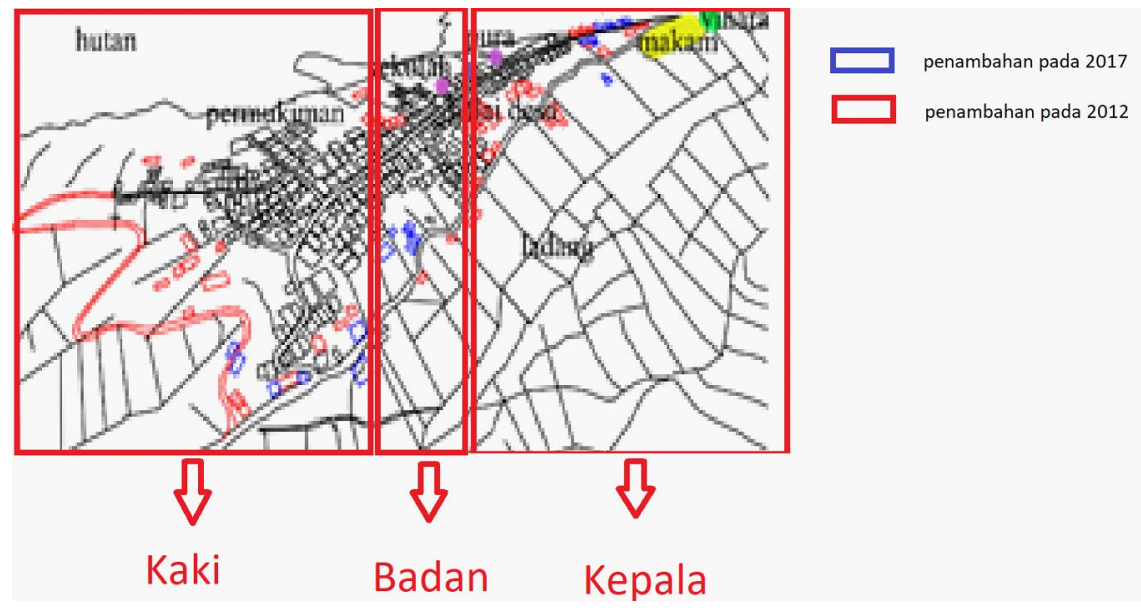

Gambar 2. Zonasi Desa Ngadas

(Sumber: diolah dengan AutoCAD 2014)

Meskipun secara umum aturan mengenai penempatan bangunan masih terjaga, terdapat pergeseran yang terjadi akibat adanya kegiatan pariwisata. Area foto baru dan warung, diletakkan di sekitar makam dan vihara. Artinya, area suci tidak lagi memiliki satu fungsi saja, dengan adanya pariwisata, fungsi dan bangunan juga bertambah untuk menunjang kegiatan wisata. Selain kegiatan wisata, perubahan morfologi juga disebabkan adanya kegiatan pertanian, sehingga banyak dibangun rumah ladang dan tempat penyimpanan hasil pertanian (Gambar 3). 


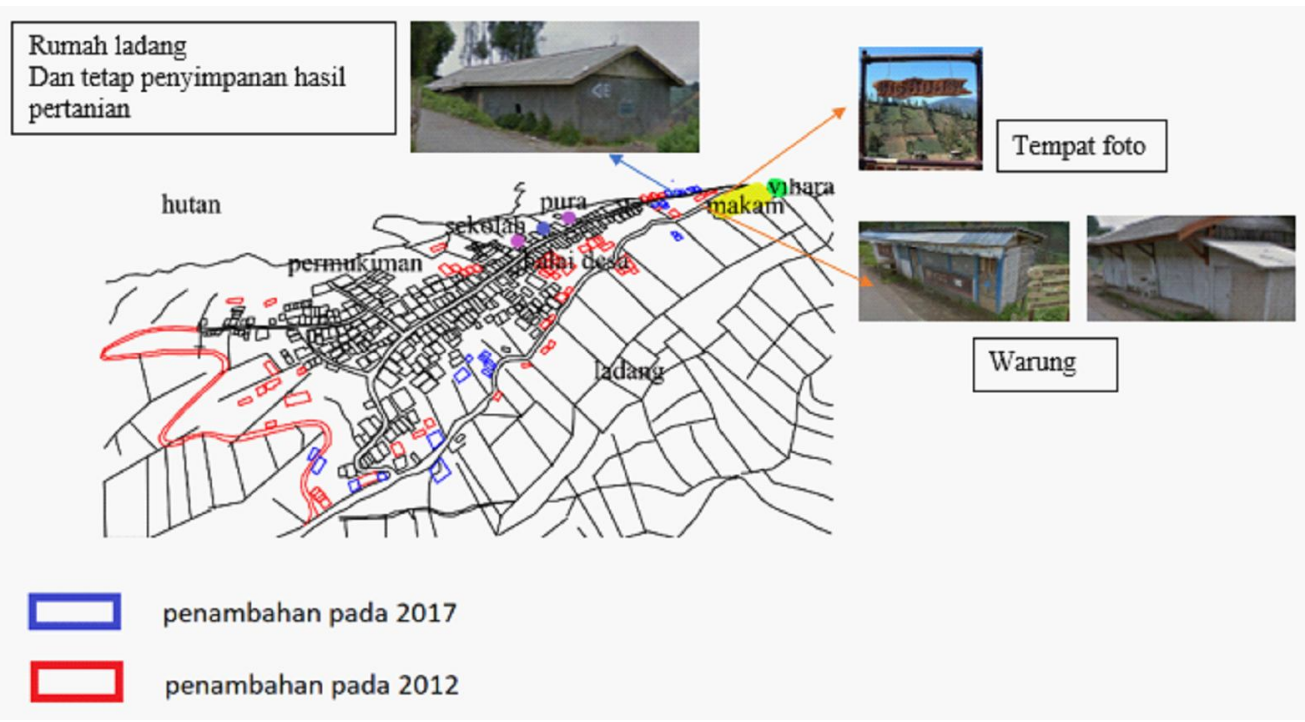

Gambar 3. Penambahan fungsi bangunan

(Sumber: Analisis peneliti)

Sementara itu, di zona badan dan kaki, massa bangunan didominasi oleh hunian. Hal ini terus bertambah seiring dengan berjalannya waktu. Terdapat dua tipe perkembangan hunian, pertama di depan hunian eksisting, dan di belakang hunian eksisting. Perkembangan di depan hunian diakibatkan adanya kegiatan wisata. Sehingga, berkembang homestay dan warung di kawasan tersebut. Sementara itu, perkembangan ke arah belakang dipengaruhi oleh aturan pembangunan rumah baru bagi anak yang telah berkeluarga harus berada di belakang rumah utama atau rumah orang tua (Endarwati, 2013).

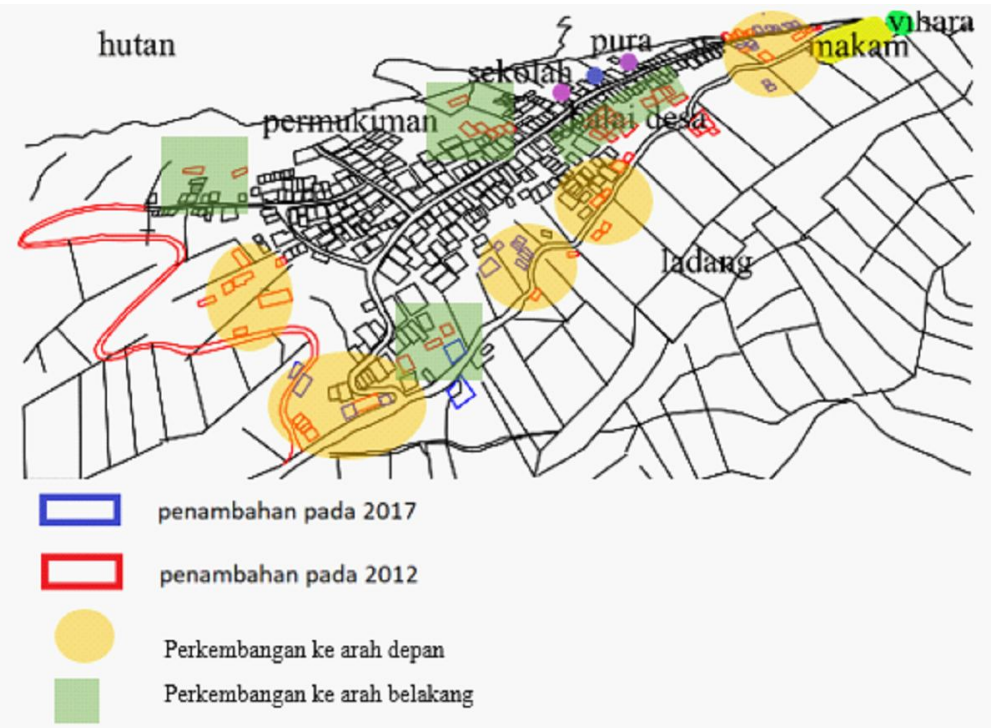

Gambar 4. Perkembangan masa bangunan

(Sumber: Analisis peneliti) 


\section{Faktor Penyebab Perubahan Morfologi Desa Ngadas, Poncokusumo, Kabupaten Malang}

Dian Kartika Santoso \& Respati Wikantyoso

Pertambahan masa bangunan tidak dapat dipisahkan dari meningkatnya jumlah penduduk dan kepadatan penduduk. Peningkatan tersebut dapat dilihat pada tabel 3.

Tabel 3. Kepadatan Penduduk (Diolah dari: BPS)

\begin{tabular}{cccc}
\hline Tahun & Jumlah Penduduk (jiwa) & Luas wilayah (km2) & Kepadatan penduduk (jiwa /km2) \\
\hline $\mathbf{2 0 0 4}$ & 771 & 3,95 & 195,19 \\
\hline $\mathbf{2 0 1 2}$ & 1730 & 3,95 & 473,97 \\
\hline $\mathbf{2 0 1 7}$ & 1998 & 3,95 & 505,82 \\
\hline
\end{tabular}

\section{Pola Plot}

Pola plot eksisting dari Desa Ngadas dapat dilihat dari kondisi eksisting pada tahun 2004. Pola plot bersifat mengelompok di tengah-tengah Desa. Hal ini karena kondisi lahan yang relatif datar (Subadyo, 2016). Pada tahun 2012, kondisi plot yang mengelompok, perlahan berubah dengan adanya kelompok bangunan baru yang terletak di sekitar jalan, hal ini juga terjadi hingga tahun 2017.

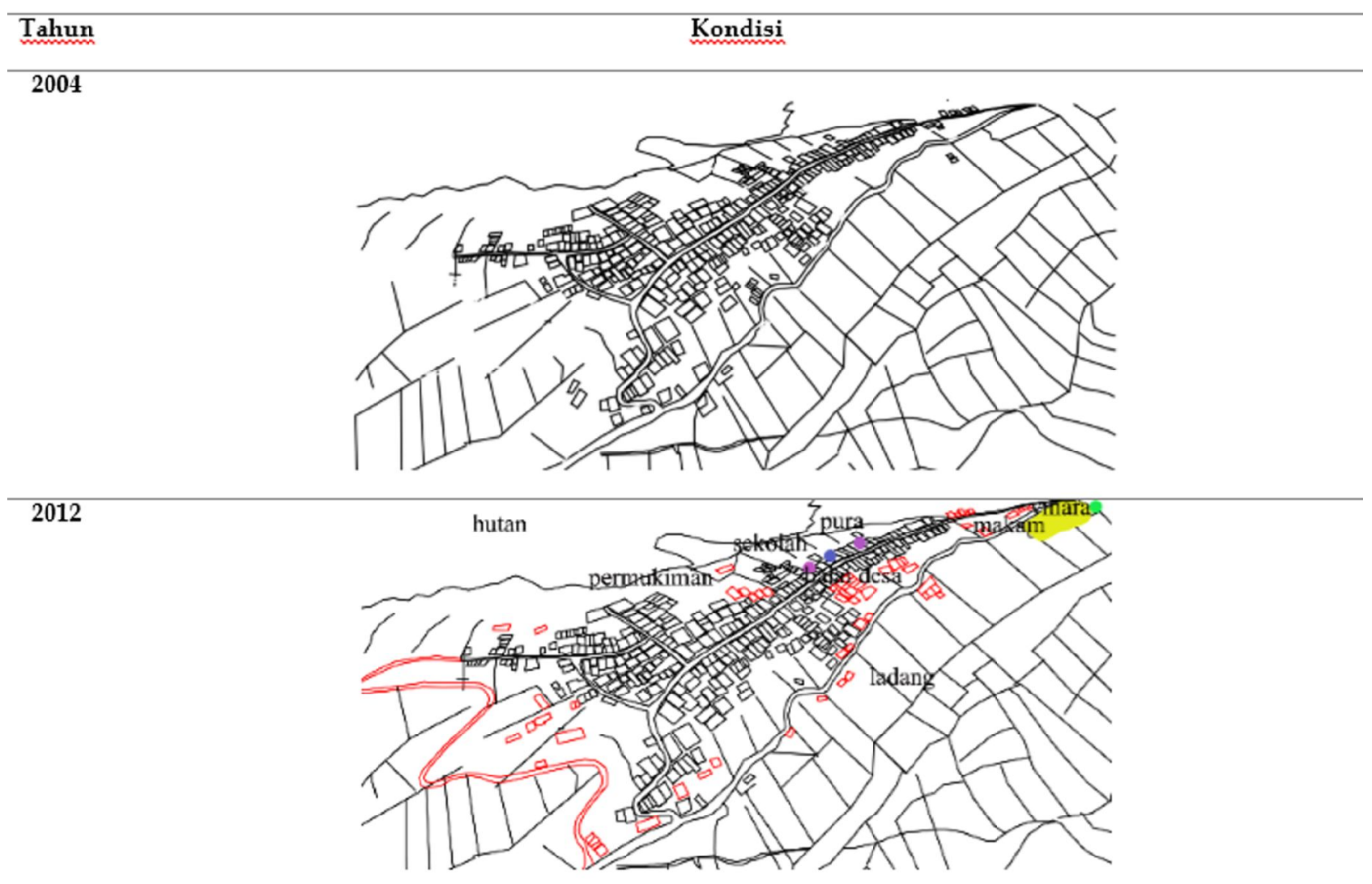




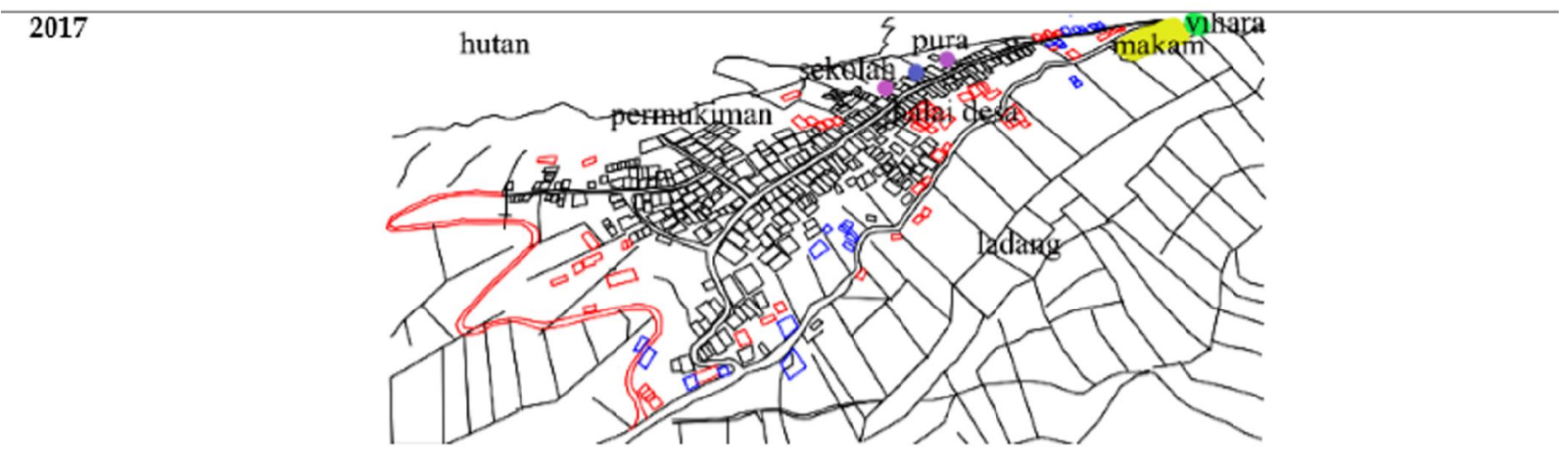

\section{Sirkulasi}

Desa Ngadas dahulu dikenal sebagai Desa yang terisolir karena akses yang sulit (Agustapraja, 2017). Namun setelah ditetapkan sebagai kawasan wisata, pemerintah mengeluarkan berbagai kebijakan yang mendukung. Peraturan Daerah No.03 Tahun 2010 tentang Rencana Tata Ruang Wilayah Kabupaten Malang menyebutkan pengalokasian dana untuk jalan lokal primer yang merupakan akses ke Gunung Bromo. Pada Tahun 2012 jalan tersebut sudah direalisasikan. Sehingga hingga tahun 2017, jalan lokal primer merupakan jalur ke bromo, sedangkan jalan lingkungan digunakan untuk aktivitas warga. Jadi, peran kebijakan pemerintah dan sektor wisata merupakan salah satu faktor yang menyebabkan perubahan morfologi Desa Ngadas.

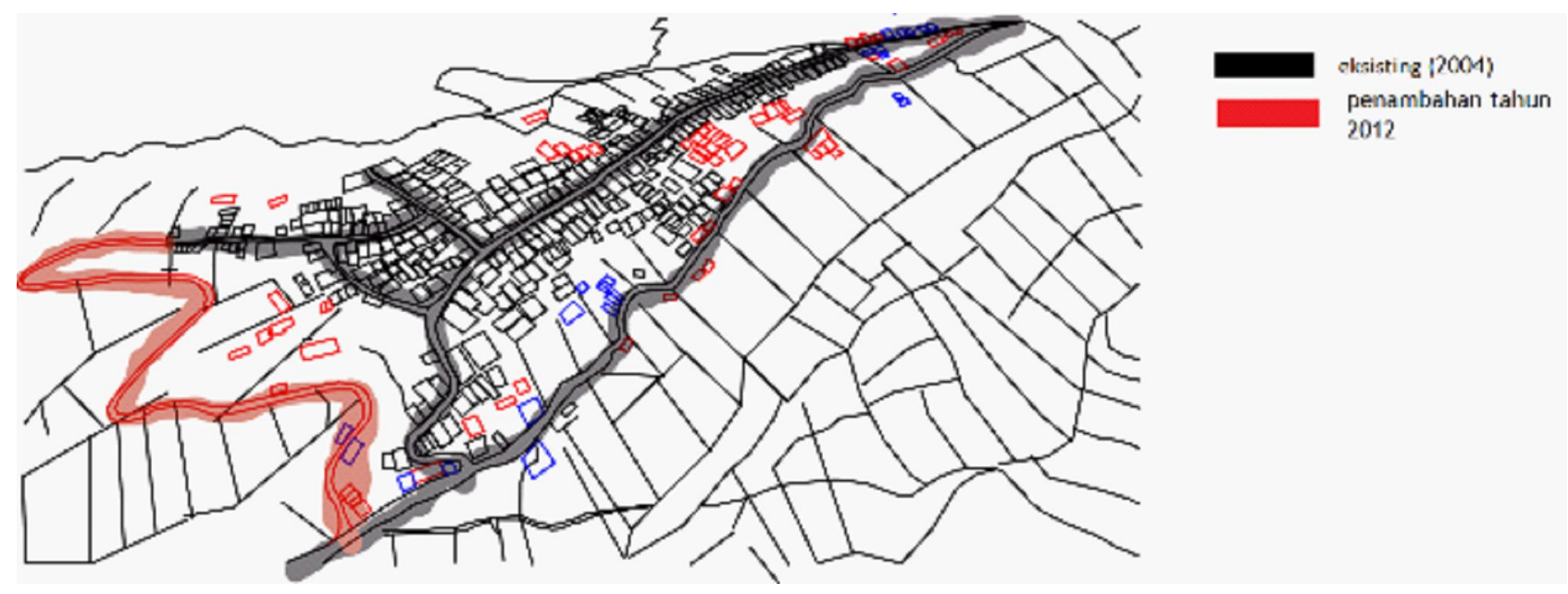

Gambar 5. Perubahan Sirkulasi

(Sumber: Analisis peneliti) 


\section{Faktor Penyebab Perubahan Morfologi Desa Ngadas, Poncokusumo, Kabupaten Malang}

Dian Kartika Santoso \& Respati Wikantyoso

\section{Kesimpulan}

Dari uraian di atas, dapat disimpulkan bahwa terdapat beberapa faktor yang mempengaruhi perubahan morfologi Desa Ngadas. Faktor alam berupa kontur tanah menyebabkan pola permukiman yang berkelompok. Faktor demografi berupa jumlah penduduk juga berakibat pada jumlah dan kepadatan masa bangunan. Faktor budaya waris mengakibatkan pola permukiman yang berkembang ke arah belakang. Selain itu, faktor pariwisata membuat adanya perubahan tata masa bangunan dan peruntukan bangunan, dari semula hanya hunian, kini berubah menjadi homestay maupun warung. Di area yang dianggap suci sekalipun, kini dibangun fasilitas wisata berupa spot foto dan berdiri beberapa warung milik warga. Kebijakan pemerintah juga turut andil dalam perubahan morfologi dalam hal penambahan jalur sirkulasi berupa jalan lokal primer baru menuju ke Bromo. Selanjutnya, jalan tersebut juga memicu berdirinya tempat-tempat usaha milik masyarakat di bidang pariwisata serta berdampak pada perekonomian Kawasan.

\section{Referensi}

Agustapraja, H. R. (2017). Penerapan Genius Loci Pada Pemukiman Masyarakat Ngadas Tengger Malang. Jurnal CIVILLa, Vol 2(No 1).

Andriyani. (2017). Pemberdayaan Masyarakat Melalui Pengembangan Desa Wisata dan Implikasinya Terhadap Ketahanan Sosial Budaya Wilayah (Studi di Desa Wisata Penglipuran Bali). JURNAL KETAHANAN NASIONAL, VOLUME 23 (No. 1), 1-16.

Anggiana, V., \& Bergas. (2014). Pembangunan Pariwisata dan Perampasan Ruang Hidup Rakyat: KSPN Menjawab Masalahnya Siapa? Retrieved from

Ayuninggar, D. P., Antariksa, \& Wardhani, D. K. (2012). Pola Hunian Tempat Tinggal Masyarakat Tengger Desa Wonokitri Kabupaten Pasuruan. Jurnal Tesa Arsitektur, Vol. 10 (No.1).

Ayuninggar, D. P., Antariksa, A., \& Wardhani, D. K. (2013). Sosial Budaya Pembentuk Permukiman Masyarakat Tengger Desa Wonokitri, Kabupaten Pasuruan. Jurnal Tata Kota dan Daerah, Vol 5(No 1).

Carmona. (2003). Public Space Urban SpaceThe Dimention of Urban Design. London: Architectural Press London.

Endarwati, M. C. (2013). Pengaruh Mitos Pada Bentukan Ruang Bermukim Di Desa Ngadas Kecamatan Poncokusumo Kabupaten Malang. Jurnal Tesa Arsitektur, Vol 11(No 1).

Hidayatun, M. I., Prijotomo, J., \& Rachmawati, M. (2014). Arsitektur Nusantara Sebagai Dasar Pembentuk Regionalisme Arsitektur Indonesia. Paper presented at the Seminar Rumah Tradisional 2014 - Transformasi Nilai-nilai Tradisional dalam Arsitektur Masa Kini.

Listiyana, A., \& Mutiah, R. (2017). Pemberdayaan Masyarakat Suku Tengger Ngadas Poncokusumo Kabupaten Malang Dalam Mengembangkan Potensi Tumbuhan Obat Dan Hasil Pertanian Berbasis “Etnofarmasi” Menuju Terciptanya Desa Mandiri. Journal of Islamic Medicine, 1(1), 1. doi:10.18860/jim.v1i1.4117

Malarvizhi, K., Kumar, S. V., \& Porchelvan, P. (2016). Use of High Resolution Google Earth Satellite Imagery in Landuse Map Preparation for Urban Related Applications. Procedia Technology, 24, 1835-1842. doi:10.1016/ j.protcy.2016.05.231

Nadjmi, N. (2016). Perkembangan Pola Tata Ruang Kawasan Destinasi Pariwisata Kepulauan di Pulau Karimun Kepulauan Riau. Paper presented at the TEMU ILMIAH IPLBI 2016. 
LOCAL WISDOM, Vol. 10 No. 2 Juli 2018

Local Wisdom Scientific Online Journal

Pulighe, G., \& Lupia, F. (2016). Mapping spatial patterns of urban agriculture in Rome (Italy) using Google Earth and web-mapping services. Land Use Policy, 59, 49-58. doi:10.1016/j.landusepol.2016.08.001

Subadyo, A. T. (2016). Arsitektur Pekarangan Suku Tengger di Kantung Taman Nasional Bromo Tengger Semeru. Paper presented at the TEMU ILMIAH IPLBI 2016.

Zurqani, H. A., Post, C. J., Mikhailova, E. A., Schlautman, M. A., \& Sharp, J. L. (2018). Geospatial analysis of land use change in the Savannah River Basin using Google Earth Engine. International Journal of Applied Earth Observation and Geoinformation, 69, 175-185. doi:10.1016/j.jag.2017.12.006 